\title{
Educação matemática e educação ambiental nos anos finais do ensino fundamental: relações possíveis no cotidiano escolar
}

\author{
Mathematical education and environmental education in the final years \\ of elementary school: possible relationships in school education
}

\author{
1 Flavio Pereira de Jesus flavio2128@yahoo.com.br \\ 2 Elcione Ramos da Conceição elcioneramos.2008@hotmail.com \\ 2 Lilian Pittol Firme de Oliveira Ipfoliveira@gmail.com
}

\footnotetext{
Universidade Federal do Espírito Santo

2 Faculdade Vale do Cricaré
}

\section{Resumo}

No intento de consolidar as relações entre o ensino de Matemática e a preservação ambiental, o presente artigo considera os aportes legais e pedagógicos dos Anos Finais do Ensino Fundamental, as delimitações da disciplina Matemática para essa etapa da Educação Básica, os conceitos e práticas atuais de educação ambiental e as relações possíveis entre o ensino de Matemática e a educação ambiental na atualidade, mediante as práticas pedagógicas do cotidiano escolar, partindo do seguinte problema: como o ensino de Matemática nos Anos Finais do Ensino Fundamental pode relacionar-se pedagogicamente à temática educação ambiental? Para tanto, a pesquisa se define metodologicamente por bibliográfica, evidenciando a LDB (Lei 9394/96), a Base Nacional Comum Curricular, as Diretrizes Curriculares Nacionais (2013) para o Ensino Fundamental diante das acepções do ensino de Matemática para a educação brasileira. Traz, ainda, os conceitos de educação ambiental no cotidiano escolar sustentados por Guimarães (1992), Dias (2004) e Burak (1992). As conclusões da pesquisa apontam para a necessidade de todas as áreas do conhecimento, de modo interdisciplinar e transdisciplinar, atentarem-se para a necessidade da efetivação, por meio de planejamento, de ações pedagógicas que intercalem todos os conteúdos do ensino, inclusive a Matemática, à educação ambiental como uma necessidade emergente de reflexão e efetivação de práticas de preservação ambiental em prol de toda a humanidade.

\section{Palavras-chave}

Ensino fundamental. Matemática. Preservação ambiental.

\begin{abstract}
In an attempt to consolidate the relationships between mathematics teaching and environmental preservation, this article considers the legal and pedagogical contributions of the Final Years of Elementary School, the delimitations of the Mathematics discipline for this stage of Basic Education, the current concepts and practices of environmental education and the possible relations between the teaching of Mathematics and environmental education in the present time, through the pedagogical practices of the school daily life, starting from the following problem: how the teaching of Mathematics in the initial years of Elementary Education can relate pedagogically to the theme environmental education? To do so, the research is defined methodologically as literature review, evidencing the LDB 9394/96, the National Curricular Common Base, the National Curricular Guidelines (2013) for Elementary Education through the meanings of Mathematics Education for Brazilian Education and brings the concepts of environmental education in the daily school life supported by Guimarães (1992), Dias (2004) and Burak (1992). The conclusions of the research point to the need of all areas of knowledge, in an interdisciplinary and transdisciplinary way, to be attentive to the need of effectiveness through planning pedagogical actions that intercalate all contents of teaching, including Mathematics, to environmental education as an emerging need for reflection and implementation of environmental preservation practices for the benefit of all humanity.
\end{abstract}

\section{Keywords}

Elementary school. Mathematics. Environmental preservation.

\section{Como você deve citar?}

JESUS, Flavio Pereira de; CONCEIÇÃO, Elcione Ramos da; OLIVEIRA, Lilian Pittol Firme de. Educação matemática e educação ambiental nos anos finais do ensino fundamental: relações possíveis no cotidiano escolar. Cadernos UniFOA, Volta Redonda, n. 42, p. $67-74$, abril, 2020. 


\section{INTRODUÇÃO}

A educação no Brasil carrega consigo uma história de desafios e possibilidades. Desafios, pois ainda traz ranços de uma educação excludente e autoritária, arraigada em regimes políticos oligárquicos e ditatoriais que consideravam, muitas vezes, a educação como consequência de interesses e necessidades políticas e econômicas, dando a ela uma característica descontextualizada e distante das questões sociais e ambientais. E possibilidades, uma vez que, nas últimas décadas, encontra-se inserida em um universo intenso de debates por uma educação de qualidade, que considera os aspectos qualitativos em detrimento aos quantitativos, em prol de uma educação integral, inserida nas temáticas da atualidade, como a questão ambiental.

Ademais, ao definir as estruturas históricas da educação no Brasil, Aranha (2006) delineia que o homem é sujeito histórico e, assim, por meio da educação crítica e reflexiva, se torna um sujeito crítico para romper paradigmas.

No contexto dos debates educacionais, estruturam-se os Anos Finais do Ensino Fundamental, uma etapa da Educação Básica que no Brasil está sustentada legalmente pela Lei de Diretrizes e Bases da Educação 9394/96 e, pedagogicamente, pelas Diretrizes Curriculares Nacionais (2013), além da Base Nacional Comum Curricular. A essa educação, destinam-se visões de uma educação pautada na interdisciplinaridade e na transdisciplinaridade, ou seja, em que o processo de ensino-aprendizagem se consolide como uma educação integral, para a vida, em que os conteúdos do ensino sejam direcionados partindo do cotidiano discente e suas temáticas, considerando os saberes de todos os sujeitos.

Logo, insere-se, nesse contexto, a educação ambiental, uma temática plenamente interligada aos conteúdos do currículo escolar nas variadas disciplinas, dentre elas, a Matemática, disciplina obrigatória no currículo dos Anos Finais do Ensino Fundamental que tem buscado superar os elementos de uma educação tradicional e descontextualizada, se relacionando pedagogicamente às temáticas necessárias da atualidade.

Desse modo, esta pesquisa busca respostas para a seguinte questão: Como o ensino de Matemática nos Anos Finais do Ensino Fundamental pode relacionar-se pedagogicamente com a temática educação ambiental?

O objetivo geral da pesquisa é analisar as eventuais relações entre o ensino de Matemática nos Anos Finais do Ensino Fundamental e a temática educação ambiental, por meio das práticas pedagógicas do cotidiano escolar. Assim, os objetivos específicos são: caracterizar pedagógica e legalmente os Anos Finais do Ensino Fundamental; verificar as relações existentes entre o ensino de Matemática e a temática educação ambiental no cotidiano escolar e; identificar no campo pedagógico, práticas pedagógicas que consolidem a relação entre a Matemática e práticas de preservação ambiental na atualidade, como consequência da educação ambiental.

Metodologicamente, a pesquisa se caracteriza como bibliográfica, como explica Freitas (2013):

Pesquisa Bibliográfica: quando elaborada a partir de material já publicado, constituído principalmente de: livros, revistas, publicações em periódicos e artigos científicos, jornais, boletins, monografias, dissertações, teses, material cartográfico, internet, com o objetivo de colocar o pesquisador em contato direto com todo o material já escrito sobre 0 assunto da pesquisa (p.54).

Portanto, realizar esta pesquisa torna-se relevante para que os discentes, docentes e todos os envolvidos no contexto educacional percebam que o ensino de Matemática vai além das estruturas numéricas, seus códigos, leis e fórmulas, e que, na contemporaneidade, é possível ensinar a aprender Matemática para a vida por meio de uma educação relacionada à questão ambiental. 


\title{
2 PROCEDIMENTOS
}

Este estudo caracteriza-se como uma pesquisa bibliográfica, uma vez que a pesquisa consistiu da análise e interpretação de livros e artigos científicos disponibilizados na internet, relacionados ao assunto estudado.

O método de abordagem desta pesquisa é o dialético, pois o foco é a contraposição e contradição de ideias que levam a outras ideias, perspectiva na qual "as coisas não são analisadas na qualidade de objetos fixos, mas em movimento" (MARCONI; LAKATOS, 2007, p.101).

A estrutura do trabalho é composta pela introdução da pesquisa, suas inquietações, definidas pelos objetivos, problema de pesquisa e justificativa. Também fazem parte da estrutura a caracterização metodológica e o referencial que sustenta seu objetivo geral (que é analisar as possíveis relações entre o ensino de Matemática nos Anos Finais do Ensino Fundamental e a temática educação ambiental por meio das práticas pedagógicas do cotidiano escolar desenvolvidas nas aulas de Matemática).

São discutidas, neste trabalho, as seguintes vertentes: Matemática e o Ensino Fundamental: Aportes Legais e Pedagógicos, título destinado à caracterização dessa etapa da educação no Brasil, Interdisciplinaridade e Transdisciplinaridade no Ensino de Matemática como caminhos possíveis para as relações pedagógicas entre os conteúdos do ensino de Matemática e a preservação ambiental. Em seguida, este trabalho conceitua a educação ambiental na atualidade e, por fim, o último título, Matemática e educação ambiental, sugere algumas práticas pedagógicas possíveis de se realizar no cotidiano escolar relacionando a Matemática à temática educação ambiental.

\section{MATEMÁTICA E ENSINO FUNDAMENTAL ANOS FINAIS: APORTES LEGAIS E PEGAGÓGICOS}

Tanto a visão do que é a educação - quanto a sua qualidade - são vertentes que relacionam-se ao contexto histórico, no qual os sujeitos estão inseridos, visto que o homem é devido àquilo que lhe foi possibilitado no campo educacional. A educação é um processo social e histórico, caracterizando-se pelos preceitos norteadores de cada povo, seus sujeitos, grupos sociais, histórias e memórias. No que concerne à estrutura legal, no Brasil, são os Parâmetros Curriculares Nacionais (PCNs) e as Diretrizes Curriculares Nacionais (DCNs) que definem os objetivos gerais da educação para cada etapa da Educação Básica.

\footnotetext{
A Lei $n^{\circ} 11.274$, de 6 de fevereiro de 2006, altera a redação da LDB, dispondo sobre a duração de 9 (nove) anos para o Ensino Fundamental, com matrícula obrigatória a partir dos 6 (seis) anos de idade, e concedendo aos sistemas de ensino o prazo até 2009 para que procedam às devidas adequações de modo que a partir de 2010 esse Ensino Fundamental de 9 (nove) anos seja assegurado a todos. (BRASIL, 2013, p.109)
}

Ainda sob a ótica das DCNs, que direcionam seus preceitos pedagógicos (2013):

\begin{abstract}
O Ensino Fundamental com duração de 9 (nove) anos abrange a população na faixa etária dos 6 (seis) aos 14 (quatorze) anos de idade e se estende, também, a todos os que, na idade própria, não tiveram condições de frequentá-lo. É obrigatória a matrícula no Ensino Fundamental de crianças com 6 (seis) anos completos ou a completar até o dia 31 de março do ano em que ocorrer a matrícula, nos termos da Lei e das normas nacionais vigentes. (p.109)
\end{abstract}

A Lei de Diretrizes e Bases da Educação estabelece que a carga horária mínima anual do Ensino Fundamental regular será de oitocentas horas relógio, distribuídas em, pelo menos, duzentos dias de efetivo trabalho escolar. No Brasil, é a LDB que ampara legalmente as estruturas da educação. Nesse cenário, insere-se dentre outras áreas do conhecimento, como disciplina escolar, a Matemática. 
Além das acepções legais que estruturam a educação brasileira, existem as vertentes pedagógicas que orientam o desenvolvimento das atividades em cada área do conhecimento nos Anos Finais do Ensino Fundamental. Nesse entendimento, insere-se a disciplina Matemática, conforme definem as DCNs:

\begin{abstract}
Art. 14. A base nacional comum na Educação Básica constitui-se de conhecimentos, saberes e valores produzidos culturalmente, expressos nas políticas públicas e gerados nas instituições produtoras do conhecimento científico e tecnológico; no mundo do trabalho; no desenvolvimento das linguagens; nas atividades desportivas e corporais; na produção artística; nas formas diversas de exercício da cidadania; e nos movimentos sociais. $\S 1^{\circ}$ Integram a base nacional comum nacional: a) a Língua Portuguesa; b) a Matemática (BRASIL, 2013, p.28).
\end{abstract}

A Matemática é uma ciência que possui saberes arraigados junto à história da humanidade. Os cálculos, medidas e demais estruturas matemáticas surgiram no passado, como necessidade e habilidade humana para sua qualidade de vida e estrutura social e foram se aperfeiçoando ao longo do tempo. Em conformidade com esse prisma, que relaciona os conhecimentos matemáticos às estruturas sociais, é preciso lembrar dos Parâmetros Curriculares Nacionais (BRASIL, 1998, p. 61): "identificar os conhecimentos matemáticos como meios para compreender e transformar o mundo a sua volta e perceber o caráter de jogo intelectual, característico da Matemática".

Assim, entende-se que a visão geral do Ensino de Matemática para os anos finais do Ensino Fundamental compreende uma etapa que lida com um discente na adolescência, etapa da vida que interfere em seu desenvolvimento físico, emocional e psicológico e que repercute fortemente no comportamento, requer do docente o planejamento de práticas pedagógicas que se relacionem ao cotidiano, despertando interesse dos estudantes, métodos ativos que liguem os conteúdos de matemática às vivências cotidianas, que podem representar um caminho de sucesso.

Outro ponto de reflexão para o docente é que o planejamento das aulas precisa acontecer de modo efetivo para que se consiga levar em conta as temáticas do cotidiano para ensinar Matemática, "discutindo [...] como pode contribuir para a solução tanto de problemas do cotidiano, como de problemas ligados à investigação científica" (BRASIL, 1998, p.62). Desse modo, o estudante poderá identificar o conhecimento matemático como meio que o permita a melhor forma de compreender e atuar na comunidade em que se encontra inserido, tornando os saberes matemáticos parte de seu cotidiano.

Ensinar Matemática pode ser uma ação de partilha de saberes e um campo de possibilidades, como prática ligada aos temas atuais, como a preservação ambiental. A interdisciplinaridade e a transdisciplinaridade, assim, caracterizam-se como relevantes ferramentas nesse processo e que sustentam pedagogicamente o trabalho docente.

\title{
4 INTERDISCIPLINARIDADE E TRANSDISCIPLINARIDADE NO ENSINO DE MATEMÁTICA
}

Com o objetivo de superar a educação tradicional e, consequentemente, o processo ensino-aprendizagem de Matemática distante da realidade discente, existem, nos documentos oficiais da educação brasileira e em vertentes pedagógicas, metodologias de ensino que são possibilidades para intercalar os conteúdos de Matemática às questões atuais, como a preservação ambiental.

Para Coimbra (2000), a interdisciplinaridade consiste num tema, objeto ou abordagem, em que duas ou mais disciplinas intencionalmente estabelecem nexos e vínculos entre si para alcançar um conhecimento mais abrangente e, ao mesmo tempo, diversificado. É a busca pelo entendimento comum ou partilhado e o envolvimento direto dos interlocutores, em que cada disciplina mantém sua identidade, mas troca elaborações e conclusões. 
Desse modo, abordar a temática preservação ambiental no ensino de Matemática é um caminho possível, de acordo com a Lei № 9.795, de 27 de abril de 1999, que institui a Política Nacional de Educação Ambiental. Ela delimita, em seu artigo $9^{\circ}$, que deve estar presente e ser desenvolvida no âmbito dos currículos das instituições de ensino público e privado, englobando todas as etapas da educação, inclusive o Ensino Fundamental.

A mesma lei, em seu Art. $2^{\circ}$, afirma que a educação ambiental é um componente essencial e permanente da educação nacional, devendo estar presente, de forma articulada, em todos os níveis e modalidades do processo educativo, em caráter formal e não formal.

Portanto, conforme as prerrogativas legais acima, existem saberes que vão além das disciplinas do currículo e, para amparar o professor nessa percepção, está a metodologia transdisciplinar.

A transdisciplinaridade, para Coimbra (2000), é a metodologia que dá um passo além da interdisciplinaridade no tratamento teórico de um tema, pois prevê uma autossuperação humanística. No entanto, precisa ser concebida como um processo bem ordenado e planejado.

A transdisciplinaridade surge da necessidade de superar as barreiras das disciplinas. Nessa visão, as disciplinas existem, mas os saberes e reflexões gerados estão além das limitações das disciplinas e suas relações. São conhecimentos construídos pela vida e para a vida, considerando as realidades dos sujeitos. Assim, a transdisciplinaridade gera conhecimentos que vão além das disciplinas, mas são ações e práticas planejadas por elas. Como exemplo dessa ação está o estreitamento da relação entre educação ambiental e o ensino de Matemática.

\section{EDUCAÇÃO AMBIENTAL NA ATUALIDADE: CONCEITOS}

Para Brügger (1994, p. 27) , "a crise ambiental é, portanto, muito mais a crise de uma sociedade do que uma crise de gerenciamento da natureza", ou seja, um tema que precisa ser abordado por toda a sociedade.

O termo "Educação Ambiental" surgiu apenas nos anos 1970, sobretudo quando desponta a preocupação com a problemática ambiental. A partir de então, manifestam-se vários acontecimentos que solidificam tal questão, como a Conferência de Estocolmo, em 1972; a Conferência Rio-9, realizada no Rio de Janeiro, em 1992, que estabeleceu uma importante medida; a Agenda 21, que foi um plano de ação para o século XXI, visando à sustentabilidade da vida na terra (DIAS, 2004).

Ainda no campo das ações e das responsabilidades, para Dias (2004) a educação ambiental é

processo permanente no qual os indivíduos e a comunidade tomam consciência do seu meio ambiente e adquirem novos conhecimentos, valores, habilidades, experiências e determinação que os tornam aptos a agir e resolver problemas ambientais, presentes e futuros (p.523).

Na ótica de Guimarães (1992), a crise vivida hoje

é ecológica (esgotamento progressivo da base de recursos naturais), ambiental (redução da capacidade de recuperação dos ecossistemas) e político-institucional (ligada aos sistemas de poder para a posse, distribuição e uso dos recursos da sociedade (p.20).

Desse modo, ensinar matemática com práticas intercaladas às questões ambientais como responsabilidade coletiva é defender a visão de que é preciso que a educação matemática supere a visão 
tradicional de decodificadora de números, códigos e fórmulas e que se torne formadora de hábitos e práticas reflexivas.

Assim, ensinar na atualidade representa superação e educação para a vida, e não para os saberes isolados das disciplinas.

\begin{abstract}
Só faz sentido insistirmos em educação se for possível conseguir por meio dela um desenvolvimento pleno, e desenvolvimento pleno não significa melhores índices de alfabetização, ou melhores índices econômicos e controle da inflação, ou qualidade total na produção, ou quaisquer dos vários índices propostos por filósofos, políticos, economistas e governantes. Tudo se resume em atingirmos melhor qualidade de vida e maior dignidade da humanidade como um todo, e isso se manifesta no encontro de cada indivíduo com o outro (D'AMBRóSIO, 1998, p.9-10)
\end{abstract}

A educação ambiental precisa ser concebida como prática de responsabilidade partilhada, nas organizações, nos movimentos sociais, nas escolas, nas comunidades, nos espaços escolares e não escolares.

\title{
6 MATEMÁTICA E PRESERVAÇÃO AMBIENTAL NO ENSINO FUNDAMENTAL: CAMINHOS POSSÍVEIS
}

A Modelagem Matemática é uma ferramenta matemática que, se aliada à criatividade e ao raciocínio no cotidiano escolar, permite ao homem explorar e refletir sobre as questões de seu meio ambiente, modelando-o para melhor conhecê-lo e preservá-lo.

Nessa ótica, as palavras de Burak (1992, p. 62) definem que

\begin{abstract}
a Modelagem Matemática constitui-se em um conjunto de procedimentos cujo objetivo é construir um paralelo para tentar explicar, matematicamente, os fenômenos presentes no cotidiano do ser humano, ajudando-o a fazer predições e a tomar decisões.
\end{abstract}

A utilização da modelagem matemática como prática pedagógica em sala de aula pode se configurar em um trabalho de potencialização de saberes para os discentes à medida em que se configura como espaço dialógico das questões ambientais, colocando os discentes em contato com problemas reais, pautados pela experimentação, abstração, resolução, validação, aplicação intercalado à modificação, como, por exemplo, nas decisões acerca do melhor lugar do papel ou das latinhas de refrigerante na sociedade, como um debate social e estruturado a partir das estruturas matemáticas.

Nesse sentido, Burak (1992) esclarece que

\begin{abstract}
o papel do professor, no método da Modelagem, assume características diferentes do papel do professor na forma tradicional de ensino. Nessa proposta, o professor tem o papel de mediador da relação ensino-aprendizagem, isto é, orientador do trabalho, tirando as dúvidas, colocando novos pontos de vista com relação ao problema tratado e outros aspectos que permitam aos alunos pensarem sobre o assunto (p.292-293).
\end{abstract}

Assim, as situações e desafios dos problemas, além de potencializar o desenvolvimentos cognitivo, estimular a concentração e o raciocínio lógico, gera interação e afetividade por meio dos debates de grupo, com temas para discussão como, por exemplo, os resíduos despejados pelas indústrias nos rios e lagos, o lixo que é produzido nas residências, dentre outros temas ambientais que podem se atrelar aos conteúdos do currículo de Matemática, dando ao currículo escolar um sentido de processo vivenciado na escola.

Desse modo, vários conteúdos do ensino podem ser abordados a partir de situações-problema direcionadas à educação ambiental, como, por exemplo, pedir aos estudantes que, durante uma sema- 
na, observem e recolham a quantidade de resíduos gerados em suas residências, para que, no debate em sala, seja feita a comparação desses resultados com os colegas da turma, verificando quais são os motivadores para que ocorra uma maior produção em certos dias da semana, por que numa residência a produção é maior ou menor, entre outras razões, dentre outras reflexões que gerem aprendizagens ligadas às questões ambientais e aos conteúdos do ensino de Matemática, como grandezas e medidas.

Ainda no que concerne às questões ambientais, o ensino de Matemática pode oportunizar aos estudantes um simulador de consumo de energia, por exemplo. Com autorização dos responsáveis, cada discente poderá levar um talão de energia; com os dados, o professor pode direcionar atividades relacionadas à construção de gráficos com valores comparativos do consumo de energia e, além disso, inserir conteúdos ligados à multiplicação e divisão, por meio de situações reflexivas de preservação ambiental. 0 trabalho com os valores de consumo de energia pode ser um excelente contexto para a preparação e base dos discentes para as noções de Física e Química, por exemplo.

O professor de Matemática pode ensinar, se assim pretender, as quatro operações de modo tradicional e descontextualizado. No entanto, como professor crítico e reflexivo, pode contextualizar o conteúdo e interligá-lo às questões ambientais, convidando seus alunos para uma análise sobre o consumo de energia de cada casa dos estudantes, trabalhando, em paralelo, as questões de preservação.

Pode até mesmo ensinar modelagem, com situações-problema isoladas das realidades discentes ou atrelar ao contexto dos desafios dos problemas da modelagem matemática às vivências de temáticas ambientais, convidando a sala e aula a se tornar um ambiente investigativo e reflexivo, gerador de práticas que reforcem a importância de preservar o meio ambiente.

\section{CONSIDERAÇÕES FINAIS}

Esta pesquisa trouxe consigo a reflexão de que os educadores ainda precisam perceber efetivamente a necessidade de substituir a pedagogia tradicional e descontextualizada do saber por uma pedagogia que inclua temas da atualidade e que façam sentido na aprendizagem, como a educação ambiental.

Ao finalizar as abordagens bibliográficas e os conceitos postos na pesquisa, avaliou-se que existem subsídios teóricos e práticos que sustentam o trabalho docente em direção a uma educação matemática atrelada às questões ambientais, além de que é possível efetivar essa relação no cotidiano escolar.

A pesquisa constatou ainda que, por meio do planejamento docente, é possível direcionar os alunos no desenvolvimento de atividades críticas e reflexivas de seu cotidiano, direcionando-os nas reflexões ambientais e aprendendo Matemática por meio de uma aprendizagem integral e significativa, de forma que aprender cálculos e fórmulas representa também preservar o meio ambiente. 


\section{REFERÊNCIAS}

ARANHA, Maria Lúcia de Arruda. História da Educação. 3. ed. São Paulo: Moderna, 2006.

BRASIL. Diretrizes Curriculares Nacionais para a Educação Ambiental. In: Brasil. Ministério da Educação. Diretrizes Curriculares Nacionais Gerais da Educação Básica. Ministério da Educação. Secretaria de Educação Básica. Diretoria de Currículos e Educação Integral. Brasília: MEC, SEB, DICEI, 2013. p. 534-562.

BRASIL. MEC. Lei de Diretrizes e Bases da Educação Nacional, LDB 9.394 de 20 de dezembro de 1996. BRASIL. Parâmetros Curriculares Nacionais. Introdução. Ensino Fundamental. Brasília: MEC/SEF, 1998. BRASIL. Política Nacional de Educação Ambiental. Lei 9795/99. Brasília, 1999.

BRÜGGER, P. Educação ou adestramento ambiental? Santa Catarina: Letras Contemporâneas, 1994.

BURAK, D. Modelagem matemática: Ações e Interações no Processo de Ensino-Aprendizagem. 1992. 460 f. Tese (Doutorado em Educação) - Universidade Estadual de Campinas, Campinas.

COIMBRA, J. A. A. Considerações sobre a interdisciplinaridade. In: PHILIPPI JR., A. Interdisciplinaridade em Ciências Ambientais. São Paulo: Signus, 2000. p. 52-70.

D'AMBRÓSIO, U. Etnomatemática: Arte ou técnica de explicar ou conhecer. 5. ed. São Paulo: Ática, 1998.

DIAS, Genebaldo Freire. Educação Ambiental: princípios e práticas. 9. ed. São Paulo. Gaia, 2004.

FREITAS. Ernani. Metodologia do trabalho científico [recurso eletrônico]: métodos e técnicas da pesquisa e do trabalho acadêmico / Cleber Cristiano Prodanov, Ernani Cesar de Freitas. - 2. ed. - Novo Hamburgo: Fevale, 2013.

GUIMARÃES, R. P. O novo padrão de desenvolvimento para o Brasil: interrelação do desenvolvimento industrial e agrícola com o meio ambiente. In: VELOSO, J. R. dos R. (org.). A ecologia e o novo padrão de desenvolvimento no Brasil. São Paulo: Nobel, 1992.

MARCONI, Marina de Andrade; LAKATOS, Eva Maria. Metodologia científica: ciência e conhecimento científico, métodos científicos, teoria, hipóteses e variáveis. 5. ed. São Paulo: Atlas, 2007. 